\title{
Miscelánea
}

\section{Agua y vida. Salud pública en la Lima colonial (1535-1821), de Paula Ermila Rivasplata Varilla (Reseña)}

Water and life. Public health in colonial Lima (15351821), de Paula Ermila Rivasplata Varilla (Review)

Água e vida. Saúde pública em Lima Colonial (15351821), de Paula Ermila Rivasplata Varilla (Revisão)

José Siles González

Catedrático de la Facultad de Ciencias de la Salud de la Universidad de Alicante

Cómo citar esta reseña en edición digital: Siles-González, J. (2018). Agua y vida. Salud pública en la Lima colonial (1535-1821) de Paula Ermila Rivasplata Varilla. Cultura de los Cuidados (Edición digital), 22(52). Recuperado de <http://dx.doi.org/10.14198/cuid.2018.52.22>

Correspondencia: Departamento de enfermería. Universidad de Alicante. 03080-Alicante (España) Correo electrónico: jose.siles@ua.es Recibido - Aceptado: Reseña invitada

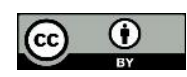

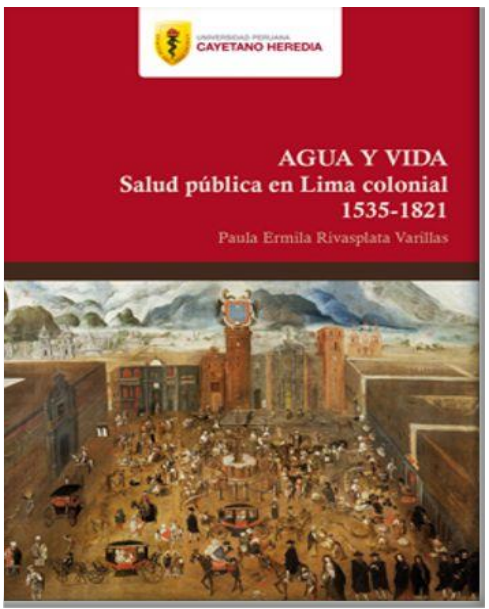

RIVASPLATA VARILLAS, Paula Ermila, Agua y Vida. Salud Pública en la Lima colonial (1535-1821), Lima (Perú), Universidad Peruana Cayetano Heredia, 2018, 620 pp. (PoRTADA)

\section{ABSTRACT}

In this study, the author performs a thorough work looking for data in various files in order to gather the appropriate material to build the history of water and public health in Lima in the colonial period.

Keywords: Social history, History of public health, water history, nursing history.

\section{RESUMO}

Neste estudo, o autor realiza um trabalho minucioso buscando dados em vários arquivos, a fim de reunir o material apropriado para a construção da história da água e da saúde pública em Lima no período colonial.

Palavras-chave: História social, história da saúde pública, história da água, história da enfermagem. 


\section{RESUMEN}

En este estudio, la autora realiza un minucioso trabajo buscando datos en diversos archivos con la finalidad de reunir el material adecuado para construir la historia del agua y la salud pública en Lima en el período colonial.

Palabras clave: Historia social, historia de la salud pública, historia del agua, historia de la enfermería.

Paula Ermila Rivasplata Varillas es una colaboradora de Cultura de los Cuidados desde hace tiempo. Su excelente trabajo ha contribuido a enriquecer el apartado histórico de la revista con la publicación de algunas de sus más destacadas publicaciones. Paula Ermila es una investigadora cuya trayectoria académica sorprende por su transdisciplinaridad y despliegue geográfico a la hora tanto de realizar sus estudios (ingeniería ambiental y de Educación en la Universidad Federico Villarreal, arqueóloga por la prestigiosa y decana universidad de San Marcos, doctora en historia contemporánea por la universidad del País Vasco y estudios de posdoctorado en la universidad de Sevilla (Literatura y poder en América), universidad Pablo Olávide de Sevilla (Ciencias sociales aplicadas al medio ambiente, el mundo contemporáneo y su difusión atlántica, etc.).

Esta obra de 620 páginas es una de las brillantes consecuencias de su transdisciplinaridad y la originalidad de su trabajo -extraordinariamente pundonorosose muestra de forma categórica desde la primera hasta la última de sus hojas. El texto dedicado, tal como se indica en el título, al estudio del agua y la salud pública en la Lima colonial se estructura en un prólogo escrito por el profesor Julián Ruíz Rivera de la Universidad de Sevilla, 5 grandes capítulos y un epílogo: I. evolución de la ciudad de los reyes; II. Instituciones de salud en Lima; III. Higiene urbana y salud pública; IV. El agua de boca; V. Vigilancia y control. Intendencia y policía; $y$, finalmente un epílogo seguido de una completa bibliografía. Además, para complementar la lectura, la autora integra 14 tablas, 13 figuras y 32 planes que resultan pertinentes dada la naturaleza del estudio. Uno de los aspectos más destacados de este estudio radica en la extensión del proceso heurístico, pues se han consultado 10 archivos (Arzobispal de Lima, General de las Indias de Sevilla, General de la Nación de Perú, Municipalidad de Lima, Municipal de Sevilla, Provincial de Sevilla, Biblioteca Nacional de Lima, Biblioteca Nacional de Madrid y el Fondo Antiguo de la Biblioteca de la Universidad de Sevilla. Pero además del número de archivos, se comprueba tras la lectura de la obra, la intensidad y profundidad con la que han sido analizadas las fuentes consultadas, por lo que tenemos entre nuestras manos un sólido producto de investigación histórica que debe ser de lectura imprescindible para los estudiosos de la salud pública en general y del abastecimiento de agua y la higiene en particular.

Para ilustrar el enfoque holístico del trabajo de la doctora Rivasplata, sirva de ejemplo el análisis de los usos del agua en algo tan específico como los molinos de pan. En este apartado se comprueba como el agua incide de forma determinante en la alimentación contribuyendo al procesamiento del trigo mediante su prensado. Otro ejemplo podría ser el apartado dedicado a las acequias que posibilitan el riego $\mathrm{y}$, por tanto la agricultura. Especialmente interesante es el capítulo dedicado al "agua de boca" y su relación con el incremento de fuentes $y$, posteriormente, en el sistema de abastecimiento que va a producir el tránsito 
del aprovisionamiento familiar o particular mediante acarreo desde fuentes a un sistema público que lleva el agua a los domicilios. En definitiva en este interesante estudio nos encontramos ante tres siglos de la historia del agua en Lima en su período colonial, pero no se trata de un estudio del agua en sí misma, sino de los factores que se derivan de la situación más o menos desarrollada de dicho elemento y conjugando todo ello con la higiene, la salud pública, la alimentación, la existencia de controles sanitarios, cuerpos médicos y, en consecuencia, el bienestar de los habitantes de Lima en el período estudiado. 